\title{
DINÂMICA DAS PROTEÍNAS SÉRICAS DE FÊMEAS BOVINAS DA RAÇA HOLANDESA NATURALMENTE INFECTADAS PELO VÍRUS DA LEUCOSE DOS BOVINOS
}

\author{
SERUM PROTEIN DYNAMICS IN HOLSTEIN COWS NATURALLY INFECTED WITH BOVINE \\ LEUKEMIA VIRUS
}

\begin{abstract}
Eduardo Harry Birgel Junior ${ }^{1}$ Lucila Cardoso de Almeida Salvatore $^{2}$ Flávia Signorini Neves $^{2}$ Regina Mieko Sakata Mirandola ${ }^{3}$ Patrício Marques de Souza $^{4}$ Eduardo Harry Birgel $^{5}$
\end{abstract}

RESUMO

Com o objetivo de avaliar a dinâmica das proteínas séricas de fêmeas bovinas da raça holandesa, criadas no Estado de São Paulo e naturalmente infectadas pelo vírus da leucose dos bovinos, foram colhidas 60 amostras de soro sangüíneo. Os animais foram divididos em 3 grupos experimentais: Grupo 1 composto de 20 fêmeas não reagentes ao antígeno gp-51 do vírus da leucose dos bovinos; Grupo 2 - composto de 20 fêmeas reagentes ao antígeno gp-5l do vírus da leucose dos bovinos sem linfocitose; Grupo 3 - composto de 20 fêmeas reagentes ao antígeno gp-5l do vírus da leucose dos bovinos com linfocitose. A avaliação do proteinograma sérico foi realizada pela determinação dos teores séricos de proteína total pelo método do biureto e a separação das frações albumina, alfaglobulina, betaglobulina e gamaglobulina através de eletroforese. A determinação quantitativa dos níveis séricos de imunoglobulinas IgM e IgG foi realizada através de imunodifusão radial simples. Os valores séricos do proteinograma e da concentração sérica das imunoglobulinas $\operatorname{IgG}$ e IgM dos animais não reagentes ao vírus da leucose dos bovinos foram semelhantes àqueles observados nos animais reagentes ao vírus da leucose dos Bovinos sem linfocitose e no grupo de animais reagentes ao vírus da leucose dos bovinos com linfocitose.

Palavras-chave: proteinograma, IgG, IgM, leucose enzoótica dos bovinos, proteínas séricas.

\section{SUMMARY}

In an attempt to determine the serum protein dynamics in cattle naturally infected with bovine leukemia virus, samples of blood sera from 60 cows of Holstein breed, raised in the State of São Paulo, Brazil, were collected.The animals were divided in three Groups: Group 1-was composed of 20 bovine leukemia virus antibody negative cows; Group 2 - was composed of 20 cows reacting to the antigen ( $g \mathrm{p}-51)$ of the bovine leukemia virus without lymphocytosis and Group 3 -was composed of 20 cows reacting to the antigen ( $g p-51)$ of the bovine leukemia virus with lymphocytosis. Serum total protein was determined by the biuret reaction and serum protein fractions (alpha, beta and gammaglobulin) by electrophoresis. Immunoglobulins IgM and Ig $G$ were determined by single radial imunodiffusion.There were no signifcant differences in the serum protein profiles and the concentration of serum IgG and IgM between the three groups (bovine leukemia virus antibody negative cows; bovine leukemia virus antibody positive cows without lymphocytosis and bovine leukemia virus antibody positive cows with lymphocytosis).

Key words: proteinogram, IgG, IgM, bovine leukosis, serum proteins.

\section{INTRODUÇÃO}

A leucose enzoótica dos bovinos é uma doença infecto-contagiosa determinada por um retrovírus, denominado vírus da leucose dos bovinos. Essa doença é caracterizada pelo aparecimento de uma sintomatologia pleomórfica em decorrência do desenvolvimento de tumorações com infiltração mononuclear em órgãos ricos em tecido linfóide como linfonodos, abomaso, coração, útero, baço, rins e alterações hematológicas, evidenciadas por leucocitose por linfocitose com aumento das formas linfocitárias atípicas (BIRGEL, 1982b).

\footnotetext{
${ }^{1}$ Médico Veterinário, Doutor, Professor Assistente, Centro de Pesquisa e Diagnóstico de Enfermidades de Ruminantes (CPDER), Departamento de Clínica Médica (DCM), Faculdade de Medicina Veterinária e Zootecnia (FMVZ), Universidade de São Paulo (USP). Av. Prof. Dr. Orlando Marques de Paiva, 87, 05508-900, Cidade Universitária, São Paulo, SP. E-mail: ehbirgel@usp.br. Autor para correspondência.

${ }^{2}$ Bolsista de Iniciação Científica da FAPESP.

${ }^{3}$ Farmacêutico, Mestre, DCM, FMVZ, USP.

${ }^{4}$ Médico Veterinário, Doutor, Professor Assistente, Departamento de Medicina Veterinária, Universidade Federal da Paraíba.

${ }^{5}$ Médico Veterinário, Professor Titular, Centro de Pesquisa CPDER, DCM, FMVZ, USP.
} 
No Brasil, desde a primeira descrição, em bovinos, de linfossarcoma (RANGEL \& MACHADO, 1943) e da comprovação científica da ocorrência da leucose enzoótica dos bovinos (MERKT et al., 1959; SANTOS $\boldsymbol{e t .}$ al., 1959) vários estudos epidemiológicos foram conduzidos. A partir da análise crítica da literatura brasileira sobre a leucose enzoótica dos bovinos, BIRGEL JUNIOR et al. (1995) consideraram ser a taxa de prevalência da leucose dos bovinos, no Brasil, igual a 29,4\%, estando esta enfermidade caracterizada como enzoótica em 11 Estados da Federação Brasileira: Acre, Bahia, Ceará, Goiás, Minas Gerais, Paraná, Pernambuco, Rio de Janeiro, Rio Grande do Sul, Rondônia e São Paulo.

Relacionado ao comportamento imunológico dos bovinos infectados pelo vírus da leucose dos bovinos encontra-se na literatura internacional compulsada um grupo de pesquisadores que acredita ser esta enfermidade responsável por distúrbios na síntese, secreção ou catabolismo da IgM, levando a uma diminuição dos valores de IgM (TRAININ et al., 1973; TRAININ et al., 1976; ATLURU et al., 1979; MEIRON et al., 1985; GATEI et al., 1990). Entretanto, MATTHAEUS \& STRAUB (1975) e MATTHAEUS (1978), relacionaram essa diminuição à presença de paraproteínas no soro de animais infectados, não havendo diminuição na síntese de IgM nos animais infectados pelo vírus da leucose dos bovinos, fato, também, observado por CREMONINI et al. (1984).

$\mathrm{O}$ assunto pouco foi pesquisado no Brasil havendo poucos trabalhos na literatura consultada. A pesquisa feita por GARCIA (1992) avaliou a resposta imune humoral e celular de bovinos sadios e infectados com o vírus da leucose dos bovinos. A resposta imune humoral foi avaliada através da imunização dos animais com vacina contra o vírus da febre aftosa e posteriores titulações semanais de anticorpos séricos contra o vírus da febre aftosa, ao longo de sete semanas, enquanto a resposta imune celular foi avaliada através da reação cutânea à tuberculina em bovinos naturalmente sensibilizados pelo Mycobacterium sp. GARCIA (1992) avaliou, também, o comportamento fenotípico dos linfócitos sangüíneos, através do emprego de quatro marcadores: imunoglobulinas de superfície, teste de formação de rosáceas, anticorpo monoclonal BLMo10 e anticorpo monoclonal M1. GARCIA (1992) concluiu que a leucose enzoótica dos bovinos não é responsável por variações imunológicas de natureza qualitativa ou funcional.

Recentemente BIRGEL et al. (1996), ao avaliarem o proteinograma de bovinos da raça
Jersey, infectados pelo vírus da leucose dos bovinos, criados em São Paulo, demonstraram a existência de diferenças estatisticamente significantes, sendo a taxa de albumina $(3,61 \pm 0,41 \mathrm{~g} / \mathrm{d} \ell)$ e a taxa da fração gamaglobulina $(1,11 \pm 0,43 \mathrm{~g} / \mathrm{d} \ell)$ obtida nos animais infectados pelo vírus da leucose dos bovinos maiores do que as taxas de albumina sérica $(3,25 \pm 0,47 \mathrm{~g} / \mathrm{d} \ell)$ e da fração gamaglobulina $(0,94 \pm 0,37 \mathrm{~g} / \mathrm{d} \ell)$ verificada nos animais sadios. Em contrapartida, o nível sérico da fração beta-2-globulina foi significativamente menor nos animais infectados $(0,90 \pm 0,34 \mathrm{~g} / \mathrm{d} \ell)$ quando comparados aos teores séricos encontrados para a fração beta-2-globulina de animais sadios $(1,14 \pm 0,38 \mathrm{~g} / \mathrm{d} \ell)$. A análise dos resultados permitiu afirmar que, em bovinos da raça Jersey, o teor sérico de proteína total, de alfaglobulina e de beta-1-globulina não sofreram variações que pudessem ser atribuídas à influência da infecção pelo vírus da leucose dos bovinos (BIRGEL et al., 1996).

A inexistência de trabalhos que avaliem a influência da infecção da leucose enzoótica dos bovinos sobre o proteinograma de bovinos da raça holandesa, bem como a ausência de pesquisas que quantifiquem as imunoglobulinas, em bovinos, criados nas condições brasileiras, motivaram a realização desta pesquisa.

\section{MATERIAL E MÉTODOS}

Para a formação dos grupos experimentais, foram colhidas, por punção da veia jugular externa, amostras de sangue de 60 fêmeas bovinas da raça holandesa, sendo 20 fêmeas não reagentes ao antígeno gp-5l do vírus da leucose dos bovinos; 20 fêmeas reagentes ao antígeno gp-51 do vírus da leucose dos bovinos sem linfocitose; e 20 fêmeas reagentes antígeno gp-51 do vírus da leucose dos bovinos com linfocitose, conforme discriminado na tabela 1.

A seleção dos animais naturalmente infectados pelo vírus da leucose dos bovinos e dos animais não reagentes ao vírus da leucose dos bovinos foi realizada por meio de avaliação sorológica utilizando-se a prova de imunodifusão dupla de Ouchterlony, em gel de ágar, empregandose o antígeno glicoprotéico (gp-51) da cápsula do vírus $^{\text {a }}$, conforme a técnica descrita por BIRGEL (1982b) e modificada por D'ANGELINO (1991). A seleção dos animais com leucocitose por linfocitose e dos animais sem alterações do quadro leucocitário (sem linfocitose) foi realizada em amostras colhidas com etilenodiamino-tetracetato-disódica (EDTA $\mathrm{Na}_{2}$ ), através de contagens do número total de leucócitos, em 
Tabela 1 - Caracterização dos grupos experimentais para avaliação da dinâmica das proteínas séricas de fêmeas bovinas da raça holandesa, criadas no Estado de São Paulo.

\begin{tabular}{lccc}
\hline Variáveis & $\begin{array}{c}\text { Grupo 1: } \\
\text { não reagentes ao } \\
\text { vírus da leucose } \\
\text { dos bovinos }\end{array}$ & $\begin{array}{c}\text { Grupo 2: } \\
\text { reagentes ao vírus da } \\
\text { leucose dos bovinos } \\
\text { sem linfocitose }\end{array}$ & $\begin{array}{c}\text { Grupo 3: } \\
\text { reagentes ao vírus da } \\
\text { leucose dos bovinos } \\
\text { com linfocitose }\end{array}$ \\
\hline $\mathrm{N}^{\circ}$ de animais & 20 & 20 & 20 \\
Idade (meses) & $41,25 \pm 13,33$ & $47,00 \pm 19,05$ & $42,75 \pm 14,34$ \\
Leucócitos & $10.432 \pm 1.857$ & $10.765 \pm 1.625$ & $30.692 \pm 6.210$ \\
Linfócitos & $7.149 \pm 1.778$ & $7.103 \pm 1.728$ & $23.992 \pm 6.892$ \\
\hline
\end{tabular}

utilizado o programa de estatística SAS Statistical Analysis System, sendo os resultados submetidos à análise de variância e o contraste das médias analisado pelo Teste de Duncan, ambos os testes com níveis de significância igual a $5 \% \quad(\mathrm{p}<0,05)$, conforme recomendam BERQUÓ et al. (1981).

\section{RESULTADOS}

Os resultados da avaliação da influência da infecção pelo vírus da

Câmara de Neubauer modificada, utilizando-se como solução diluidora o líquido de Thoma e a contagem diferencial de leucócitos em esfregaços sanguíneos corados pelo Corante de Rosenfeld, conforme a metodologia padronizada por BIRGEL (1982a).

As amostras de soro sangüíneo, destinadas à determinação do proteinograma e à quantificação das imunoglobulinas, foram colhidas em tubos de vidro siliconizados, com vácuo suficiente para aspirar $10 \mathrm{~m} \ell$ de sangue, sendo as amostras mantidas em temperatura ambiente até a coagulação. A seguir, os soros foram separados por centrifugação a $1000 \mathrm{~g}$, durante 15 minutos e transferidos para frascos de vidro, estéreis e secos, sendo conservados em congelador a $-20^{\circ} \mathrm{C}$ até a realização dos exames.

A determinação dos teores séricos de proteína total foi feita através do método do biureto, de acordo com técnica preconizada por GORNALL $\boldsymbol{e} t$ al. (1949) e modificada por STRUFALDI (1987). A migração eletroforética para a separação das frações protéicas do soro sangüíneo foi realizada em fitas de celulose, sendo a leitura das frações albumina, alfaglobulina, betaglobulina e gamaglobulina efetuadas por densitometria, conforme a técnica descrita por SOUZA (1997). A determinação das imunoglobulinas séricas foi feita segundo a técnica de MANCINI et al. (1965), utilizando-se placas de ágar incorporadas com anti-soros específicos para as classes de imunoglobulinas ${ }^{\mathrm{b}}$ $\mathrm{IgG}$ e IgM de bovinos.

Para a análise estatística dos resultados foi - Teste de Duncan. leucose enzoótica dos bovinos sobre o proteinograma de bovinos da raça holandesa estão apresentados na tabela 2, sendo que, nas condições em que o experimento foi desenvolvido, não puderam ser observadas diferenças estatisticamente significantes. Os resultados da influência da infecção da leucose enzoótica dos bovinos sobre os valores das imunoglobulinas séricas $\operatorname{IgG}$ e $\operatorname{IgM}$ estão apresentados na tabela 3, não sendo constatadas diferenças estatisticamente significantes entre os três grupos experimentais.

\section{DISCUSSÃO E CONCLUSÃO}

Para as condições em que foi realizada esta pesquisa, não houve influência da infecção pelo

Tabela 2 - Teores séricos médios, desvio padrão e amplitude de variação do proteinograma de bovinos da raça holandesa não reagentes ao antígeno gp-5l do vírus da leucose dos bovinos, reagentes ao antígeno gp-5l do vírus da leucose dos bovinos sem linfocitose e reagentes antígeno gp-5l do vírus da leucose dos bovinos com linfocitose.

\begin{tabular}{|c|c|c|c|}
\hline & \multicolumn{3}{|c|}{ Grupos experimentais } \\
\hline & $\begin{array}{c}\text { Grupo 1: } \\
\text { não reagentes ao } \\
\text { vírus da leucose dos } \\
\text { bovinos }\end{array}$ & $\begin{array}{l}\text { Grupo 2: } \\
\text { reagentes ao vírus da } \\
\text { leucose dos bovinos } \\
\text { sem linfocitose }\end{array}$ & $\begin{array}{l}\text { Grupo 3: } \\
\text { reagentes ao vírus da } \\
\text { leucose dos bovinos } \\
\text { com linfocitose }\end{array}$ \\
\hline $\mathrm{N}^{\circ}$. de animais & 20 & 20 & 20 \\
\hline Proteína total $(\mathrm{g} / \mathrm{d} \ell)$ & $\begin{array}{l}8,01 \pm 0,53^{a} \\
(6,70-9,20)\end{array}$ & $\begin{array}{l}8,02 \pm 0,55^{\mathrm{a}} \\
(6,80-9,00)\end{array}$ & $\begin{array}{l}7,85 \pm 0,44^{a} \\
(7,00-8,80)\end{array}$ \\
\hline Albumina $\quad(\mathrm{g} / \mathrm{d} \ell)$ & $\begin{array}{l}3,46 \pm 0,43^{\mathrm{a}} \\
(2,32-4,25)\end{array}$ & $\begin{array}{l}3,50 \pm 0,30^{\mathrm{a}} \\
(2,73-4,15)\end{array}$ & $\begin{array}{l}3,41 \pm 0,39^{a} \\
(2,38-4,20)\end{array}$ \\
\hline Alfaglobulina $(\mathrm{g} / \mathrm{d} \ell)$ & $\begin{array}{l}0,79 \pm 0,27^{\mathrm{a}} \\
(0,40-1,55)\end{array}$ & $\begin{array}{l}0,81 \pm 0,17^{\mathrm{a}} \\
(0,57-1,20)\end{array}$ & $\begin{array}{l}0,80 \pm 0,20^{\mathrm{a}} \\
(0,37-1,22)\end{array}$ \\
\hline Betaglobulina $(\mathrm{g} / \mathrm{d} \ell)$ & $\begin{array}{l}0,90 \pm 0,20^{\mathrm{a}} \\
(0,54-1,30)\end{array}$ & $\begin{array}{l}0,96 \pm 0,15^{\mathrm{a}} \\
(0,70-1,26)\end{array}$ & $\begin{array}{l}0,90 \pm 0,08^{\mathrm{a}} \\
(0,77-1,08)\end{array}$ \\
\hline Gamaglobulina $(\mathrm{g} / \mathrm{d} \ell)$ & $\begin{array}{l}2,84 \pm 0,64^{a} \\
(1,70-4,17)\end{array}$ & $\begin{array}{l}2,74 \pm 0,56^{\mathrm{a}} \\
(2,01-4,48)\end{array}$ & $\begin{array}{l}2,71 \pm 0,59^{a} \\
(1,80-4,10)\end{array}$ \\
\hline $\begin{array}{l}\text { Relação albumina- } \\
\text { globulinas }\end{array}$ & $\begin{array}{l}0,78 \pm 0,18^{\mathrm{a}} \\
(0,39-1,16)\end{array}$ & $\begin{array}{l}0,79 \pm 0,14^{\mathrm{a}} \\
(0,44-1,07)\end{array}$ & $\begin{array}{l}0,78 \pm 0,16^{\mathrm{a}} \\
(0,43-1,16)\end{array}$ \\
\hline
\end{tabular}

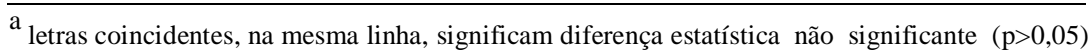

Ciência Rural, v. 31, n. 4, 2001. 
Tabela 3 - Teores séricos médios, desvio padrão e amplitude de variação das imunoglobulinas $\operatorname{IgG}$ e $\operatorname{IgM}$ de bovinos da raça holandesa não reagentes ao antígeno gp-5l do vírus da leucose dos bovinos, reagentes ao antígeno gp-5l do vírus da leucose dos bovinos sem linfocitose e reagentes antígeno gp-51 do vírus da leucose dos bovinos com linfocitose.

\begin{tabular}{cccc}
\hline & \multicolumn{3}{c}{ Grupos experimentais } \\
\cline { 2 - 4 } & $\begin{array}{c}\text { Grupo 1: } \\
\text { não reagentes ao } \\
\text { vírus da leucose } \\
\text { dos bovinos }\end{array}$ & $\begin{array}{c}\text { Grupo 2: } \\
\text { reagentes ao vírus da } \\
\text { leucose dos bovinos } \\
\text { sem linfocitose }\end{array}$ & $\begin{array}{c}\text { Grupo 3: } \\
\text { reagentes ao vírus da } \\
\text { leucose dos bovinos } \\
\text { com linfocitose }\end{array}$ \\
\hline $\mathrm{N}^{\circ}$. de animais & 20 & 20 & 20 \\
Ig G & $3.431 \pm 842^{\mathrm{a}}$ & $3.710 \pm 1.174^{\mathrm{a}}$ & $4.275 \pm 1.428^{\mathrm{a}}$ \\
$(\mathrm{mg} / \mathrm{d} \ell)$ & $(2.268-5.880)$ & $(1.680-7.665)$ & $(1.680-7.035)$ \\
Ig M & $317 \pm 143^{\mathrm{a}}$ & $323 \pm 167^{\mathrm{a}}$ & $289 \pm 130^{\mathrm{a}}$ \\
$(\mathrm{mg} / \mathrm{d} \ell)$ & $(150-600)$ & $(10-720)$ & $(100-550)$ \\
\hline
\end{tabular}

a letras coincidentes, na mesma linha, significam diferença estatística não significante $(p>0,05)$ Teste de Duncan.

vírus da leucose dos bovinos sobre o proteinograma de fêmeas bovinas da raça holandesa. Desta forma, não foram confirmados os resultados anteriores obtidos por BIRGEL et al. (1996), que ao avaliarem os resultados do proteinograma sérico de bovinos da raça Jersey, criados em São Paulo, concluíram que a infecção pelo vírus da leucose do bovinos é responsável por diferenças estatísticas significantes no proteinograma. Estas diferenças, entretanto, mesmo quando presentes, são de pequena magnitude, e como já fora salientado por MATTHAEUS \& STRAUB (1965), insuficientes para que o proteinograma seja utilizado no diagnóstico da leucose enzoótica dos bovinos. Com bas nas observações obtidas nesta pesquisa e na avaliação crítica da literatura compulsada demonstra-se que na avaliação das disproteinemias, em bovinos, a infecção pelo vírus da leucose dos bovinos é fator de pouca influência quantitativa, podendo mesmo ser esta influência desconsiderada.

$$
\text { Os resultados desta pesquisa }
$$
demonstraram não haver diferenças nas concentrações séricas das imunoglobulinas IgM, em fêmeas bovinas da raça holandesa sadias ou infectadas pelo vírus da leucose dos bovinos, resultados estes que estão em concordância com as observações de MATTHAEUS \& STRAUB (1975), MATTHAEUS (1978) e CREMONINI et al. (1984). $\mathrm{Na}$ presente pesquisa, não foram observados os distúrbios relacionados ao metabolismo da $\operatorname{IgM}$ citados por outros autores (TRAININ et al., 1973; TRAININ et al., 1976; ATLURU et al., 1979; MEIRON et al., 1985; GATEI et al., 1990). Relativo às concentrações de $\mathrm{IgG}$, os resultados desta pesquisa demonstraram que não houve influência da infecção pelo vírus da leucose dos bovinos, estando esses resultados em concordância com a literatura compulsada (TRAININ et al., 1973; TRAININ et $\boldsymbol{a l}$., 1976; MATTHAEUS \& STRAUB, 1975, MATTHAEUS, 1978; ATLURU et al., 1979; CREMONINI et al.,1984; MEIRON et al., 1985; GATEI et al., 1990).

As pesquisas desenvolvidas por GARCIA não puderam comprovar variações imunológicas de natureza qualitativa ou funcional. Foi sugerido por GARCIA (1992) que a leucose enzoótica é responsável apenas por variações imunológicas de natureza quantitativa, fato este que os resultados obtidos nesta pesquisa não puderam demonstrar. Apesar de a infecção pelo vírus da leucose dos bovinos ser um fator de influência para o descarte de bovinos, com os animais infectados sendo descartados com idade menor do que a idade média para o descarte de animais sadios (BIRGEL et al. 1983), e a produção leiteira dos animais infectados reduzida em $11 \%$ (D'ANGELINO, 1991), até o presente momento não foi possível uma demonstração de ser a Leucose Enzoótica dos Bovinos uma retrovirose que provoque imunossupressão, como a observada nas retroviroses dos gatos (WITTMANN \& STARICK, 1993). Esta dificuldade em se provar esses efeitos imunossupressivos está relacionada, possivelmente, aos modelos experimentais empregados.

\section{FONTES DE AQUISIÇÃO}

aLeukassay - B Pitman Moore Inc.

${ }^{\mathrm{b}}$ Bovine IgG e Bovine IgM Kits do Saikin Kagafu Institute CO, LTD.

\section{REFERÊNCIAS BIBLIOGRÁFICAS}

ATLURU, D., JOHNSON, D.W., PAUL, P.S. et al. Blymphocyte differentiation, using pokeweed mitogen stimulation: in vitro studies in leukemic and normal cattle. American Journal of Veterinary Research, v.40, p.515$520,1979$.

BERQUÓ, E.S., SOUZA, J.M.P., GOTLIEB, S.L.D. Bioestatística. São Paulo : Pedagógica e Universitária, 1981. $256 \mathrm{p}$.

BIRGEL, E.H. Hematologia clínica veterinária. In: BIRGEL, E.H., BENESI, F.J. Patologia clínica veterinária. São Paulo : Sociedade Paulista de Medicina Veterinária, 1982a. p. $2-50$. 
BIRGEL, E.H. Leucose enzoótica dos bovinos adultos: aspectos clínicos e diagnósticos. In: BIRGEL, E.H., BENESI, F.J. Patologia clínica veterinária. São Paulo : Sociedade Paulista de Medicina Veterinária, 1982b. p.249-260.

BIRGEL, E.H., BENESI, F.J., D'ANGELINO, J.L., $\boldsymbol{e t}$ al. Considerações sobre a leucose enzoótica dos bovinos adultos em rebanhos leiteiros criados no Estado de São Paulo. II Aspectos relacionados à produção In: SEMANA DE VETERINÁRIA DA FMVZ-USP, 1983, São Paulo, SP. Anais... São Paulo : FMVZ-USP, 1983. V.2, p.71.

BIRGEL, E.H, GREGORY, L., BIRGEL JUNIOR, E.H., et al. Avaliação da influência da infecção pelo vírus da Leucose dos Bovinos (VLB) sobre a função hepática e renal de animais da raça Jersey. In: CONGRESSO BRASILEIRO DE MEDICINA VETERINÁRIA, 424, 1996, Goiânia, Go. Anais... Goiânia : Sociedade Brasileira de Medicina Veterinária, 1996. p.166-167.

BIRGEL JUNIOR, E.H., D'ANGELINO, J.L., BENESI, F.J., et al. Prevalência da infecção pelo vírus leucose dos bovinos, em animais da raça Jersey, criados no Estado de São Paulo, Pesquisa Veterinária Brasileira, v.15, n.4, p.93-99, 1995.

CREMONINI, A.M., BERGAMINI, P.F., CALDORA, C., et al. Valutazione dell'anticorpoiesi in bovini infetti da BLV. Atti della Società Italiana delle Scienze Veterinarie, v.38, p.698-700, 1984.

D'ANGELINO, J.L. Leucose enzoótica dos bovinos. Estudo retrospectivo da perfomance produtiva e reprodutiva de animais infectados e não infectados. São Paulo - SP, 1991. 85p. Tese (Livre-docência) - Faculdade de Medicina Veterinária e Zootecnia, Universidade de São Paulo, 1991.

GARCIA, M. Avaliação da resposta imunitária em bovinos naturalmente infectados pelo vírus da leucose. São Paulo - SP, 1992. 60p. Tese (Doutoramento) - Faculdade de Medicina Veterinária e Zootecnia, Universidade de São Paulo, 1992.

GATEI, M.H., LAVIN, M.F., DANIEL, R.C.W. Serum immunoglobulin concentrations in cattle naturally infected with bovine leukemia virus. Journal of Veterinay Medicine, v.37B, p.575-580, 1990.

GORNALL, A.G., BARDAWILL, C.J., DAVID, M.M. Determination of serum proteins by means of biuret reaction. Journal of Biological Chemistry, v.177, p.751-766, 1949.

MANCINI, G., CARBONARA, A.O., HEREMANS, J.F. Imunochemical quantification of antigens by single radial immunodifusion. Internacional Journal of Imunochemistry, v.2, p.235-254, 1965.
MATTHAEUS, W, STRAUB, O.C. Serumelektrophoretische und hämatologische Befunde bei gesunden, an Leukose und MKS erkrankten Rindern. Berliner und Münchener Tierärztliche Wocheschrift, v.78, p.421, 1965.

MATTHAEUS, W, STRAUB, O.C. Das Serum- $\gamma$-Globulinbild bei leukosekranken Rindern und Schafen. Zentralblatt für Veterinärmedizin, v.22B, p.758-763, 1975.

MATTHAEUS, W. Heterogeneous properties of BLVprecipitatingimmunoglobulins in bovine leukemic sera. Annales des Recherches Vétérinaires, v.9, p.635-641, 1978.

MEIRON, R., BRENNER, J., GLUCKMAN, A., et al. Humoral and cellular responses in calves experimentaly infected with bovine Leukemia Virus (BLV). Veterinary Immunology and Immunopthology, v.9, p.105-114, 1985.

MERKT, H., GIUDICE, J.C.O., MÜLLER, J.A. Leucose bovina: concepção moderna e primeira verificação da doença no RS. Rev Esc Agron Vet RG Sul, v.2, p.7-19, 1959.

RANGEL, N.M., MACHADO, A.V. Contribuição à oncologia comparada em Minas Gerais. Arq Esc Sup Vet Est Minas Gerais, v.1, p.83-96, 1943.

SAS INSTITUTE. Sas user's guide: statistics. Cary : SAS Institute, 1985. 956p.

SANTOS, J.A., PINHEIRO, P.V., SILVA, L.J. Linfossarcoma com lesões da língua e câmaras cardíacas em bovinos. Anais da Escola Fluminense de Medicina Veterinária, v.2, p.1-8, 1959.

SOUZA, P.M. Perfil bioquímico sérico de bovinos das raças gir, holandesa e girolanda, criados no Estado de São Paulo. Influência de fatores de variabilidade etários e sexuais. São Paulo - SP, 1997. 168p. Dissertação (Mestrado) - Faculdade de Medicina Veterinária e Zootecnia, Universidade de São Paulo, 1997.

STRUFALDI, B. Prática de bioquímica clínica. São Paulo: Faculdade de Ciências Farmacêuticas da Universidade de São Paulo, 1987. 399p.

TRAININ, Z., MAIROM, R., KLOPFER, U., et al. Levels of IgM and IgG in the sera of normal and leukaemic cattle. Journal of Comparative Pathology, v.83, p.87-90, 1973.

TRAININ, Z., UNGAR-WARON, H., MEIROM, R., et al. IgG and IgM antibodies in normal and leukaemic cattle. Journal of Comparative Pathology, v.86., p.571-580, 1976.

WITTMANN, W., STARICK, E. Imunologie. In: WITTMANN, W. Leukosen der wiederkäuer. Stuttgart : Gustav Fischer Verlag Jena, 1993. p.113-115.

Ciência Rural, v. 31, n. 4, 2001. 